\title{
Para além das batinas
}

\author{
Prof. Dr. Mara Rúbia Sant’Anna
}

Escrever sobre moda e vestuário, nos tempos atuais, exige, antes de mais nada, uma certa clarificação do campo pelo qual estamos adentrando. Para tal evoco Elizabeth WILSON (1989), que em sua linguagem poética, questiona a impressão que todos temos de que as roupas parecem possuir uma vida própria, de tal modo que são objetos de cobiça, sedução, denunciando as pessoas em suas existência. A resposta da autora é clara à questão:

"Uma parte desta estranheza das roupas reside no facto de elas ligarem o corpo biológico com o ser social, e o público com o privado. Isto transforma o vestuário num território difícil, porque nos obriga a reconhecer que o corpo humano é mais do que uma entidade biológica. Ele é um organismo de cultura, até mesmo um artefacto cultural, e as suas próprias fronteiras não estão bem definidas(...)" (WILSON, 1989, p.10).

Hoje, como em períodos anteriores, os corpos foram vestidos, e por suas roupas e adornos expressaram uma infinidade de símbolos que permitiam a comunicação, bem como constituíam um padrão estético. 0 vestuário é sempre significativo e em suas interpretações aproximamo-nos da organicidade da sociedade que o produziu. Afinal, em seus cortes, cores, texturas, comprimentos, exotismo, as roupas dão conta de imprimir sobre os corpos que as transportam categorias sociais, ideais estéticos, 
manifestações psicológicas, relações de gêneros e de poder.

Concordando, então, que a roupa não é um produto a-histórico, o que como tal nos impediria de estabelecer qualquer ligação entre ela e a sociedade que a produziu, ousamos tomá-la como ponto de partida para discutir, pelo menos em parte, o discurso que se constituiu dentro da Instituição Eclesiástica Católica, durante a Idade Média, especificamente, durante os séculos XI e XII. Séculos nos quais essa Igreja, no Ocidente, gozou de grande efervescência, seja pela realização das Cruzadas, seja pelo surgimento das Universidades que polarizaram as fontes de produção de saber, seja pelas reformas basilares por quais passou.

A fim de que o presente artigo não tome proporções desnecessárias, delimitamos nossa discussão em torno de três pontos chaves do discurso eclesiástico medieval: a idéia de ordem, de saber e história e definimos o período entre o século XII e XIII, na Europa Ocidental, como os limites temporais da discussão. Apresentar esses três pontos chaves, discuti-los e interpretá-los a partir de alguns trajes eclesiásticos selecionados será o trilho pelo qual o trem de nossos argumentos se locomoverá, com o objetivo de estabelecer relações entre os trajes utilizados por algumas ordens religiosas católicas e em algumas cerimônias e aos discursos e propostas religiosas predominantes.

0 processo histórico, pelo qual o Cristianismo transformou-se em religião, já nos diz bastante a respeito da transcendência do 
ideal da ordem dentro da Igreja Católica. Surgida de uma diversidade ampla de interpretações das palavras do Cristo, a Igreja Católica foi constituída como fato político, no qual à custa de muitas discussões, dúvidas e brigas ferrenhas uma determinada ortodoxia encaixou-se adequadamente ao modelo político do Império Romano. Esta ortodoxia, como construção das relações de poder de certa época, transformou-se na "polícia do espírito" (QUEIROZ, 1988, p.8).

Dentre as indumentárias ${ }^{1}$ constituídas com fins eclesiais em torno do século XII, encontramse os uniformes dos Cavaleiros da Cruz Vermelha, conhecidos como Templários. O Catolicismo que reuniu esforços para reconquistar o acesso à Jerusalém, num projeto com evidentes pretensões autoritárias, realiza entre suas medidas iniciais a organização de uma ordem religiosa militar. A roupa destes cavaleiros constituía-se de uma pesada armadura de couro retorcido em malhas de ferro que cobria todo o corpo e era chamada de cota, sobreposta a ela colocava-se uma túnica circundada por cinturões e cintos e sobre tudo vinha uma capa de linho branca com uma cruz vermelha bordada. Ainda acompanhava o traje,

\footnotetext{
1 Importante destacar que o termo “indumentária” não é sinônimo de vestuário ou traje, apesar do inverso ser possível. É comum o uso indevido do termo "indumentária" em alguns autores e jornalistas que escrevem sobre o tema. Entende-se por indumentária o conjunto de peças que constituem um traje tradicional, que não se altera ao longo do tempo e nem por escolhas individuais e que possui significados atribuídos por uma tradição. Logo, o conceito de moda não se aplica a uma indumentária, moderna ou passada.
} 
deste cavaleiro, grandes cavalos, lanças e espadas $^{2}$.

Como dever militar cabia-lhe ser corajoso, lutar com espírito cristão, manter suas promessas e defender a Igreja contra qualquer infiel. A cruz vermelha simbolizava, exatamente, a união de uma religião militarizada a Deus, fazendo com que o primado da carne e do pecado fosse substituído pela ação salvadora da Igreja, da fé e da obediência ao Criador (DEMURGER, 2002).

Santo Agostinho foi fundamental na composição da teologia católica e propôs, no século $\mathrm{V}$, uma doutrina que ampliou e consolidou o ideal da ordem dentro do Catolicismo. 0 mundo, segundo o bispo de Hipona, possui uma coerência, ditada pelo poder de Deus e submetida à vontade Dele. Nesta nada foge a ordem e tudo está submetido a uma hierarquização rígida que delimita corretamente a existência, participação e importância de cada uma das criaturas no mundo (PÉPIN, 1974). O tempo cíclico da tradição popular, por exemplo, perdeu sentido e em seu lugar surgiu a linearidade da própria criação divina, que tudo encadeia e explica.

Mesmo após séculos do pensamento agostiniano ter sido fundado, a verdade concebida manteve-se a mesma, ou seja, o Universo era um todo, a criação não podia ser

\footnotetext{
${ }^{2}$ As informações pertinentes aos trajes eclesiais foram feitas mediante BRUHN, 1994.; e a gentil entrevista do Monsenhor Agostinho Stahelin, da Paróquia de São Judas Tadeu, do distrito de Barreiros, São José, S/C
} 
explicada fora de Deus, simplesmente por ser Deus o elo agregador de tudo, ponto de partida e chegada de todo empreendimento das criaturas. Portanto, a natureza, mesmo em sua maior diversidade, fazia parte de uma grande ordem, divina e cristã. 0 homem como criatura privilegiada desta criação, não fugia à regra, pois nele o microcosmo estava contido do macrocosmo e vice-versa (STEENBERGHEN, 1984).

Como toda ordenação implica em hierarquizar elementos, a idéia da ordem, fundamentada pelo Catolicismo, concebeu ao encadeamento que fez de todas as coisas, diferentes meios de estar e participar da criação. Assim sendo, todas as coisas, espiritual ou corpórea, ao serem criadas receberam de Deus uma medida, uma forma, uma ordem, uma lugar específico no mundo que thes pertencia. $\mathrm{E}$ tais lugares, medidas, formas, funções estabeleceram, conjuntamente, a hierarquia e com isso a superioridade de uns sobre os outros.

A ordem, assim estabelecida em níveis hierárquicos, permite ao ser a união a Deus mediante a escalada dos diferentes níveis de natureza, função, felicidade, saber, abandonando, gradativamente, o estágio inferior da matéria para alcançar a contemplação do espírito.

Pela natureza a ordem estabelece a mutabilidade dos seres, havendo uma hierarquia ternária que partia do mais inferior ao superior, da seguinte forma: natureza mutável no tempo e no lugar - o corpo; natureza mutável apenas no tempo - a alma e a natureza imutáveis, seja no 
tempo e no lugar - Deus. Além desta, segundo Santo Agostinho, a ordem classifica as coisas por três funções indissociáveis: ser, viver, compreender e desta forma, a pedra tem o ser corpos inanimados, o animal tem o ser e a vida seres vivos sem razão e o homem tem o ser, a vida e a inteligência - criaturas espirituais. 0 corpo, como matéria, devia ser submetido à alma, esta ao espírito e ele a Deus (OS PENSADORES, 1996).

A roupa, como dimensionada em seu poder por Wilson não tinha, conforme a ordenação católica do mundo, no período medieval, possibilidade de seduzir e ser alvo de cobiça por ela própria, pois afinal na mentalidade daqueles homens ela possuía uma natureza mutável no tempo e no lugar, tinha o ser, mas seria incapaz de proporcionar às criaturas espirituais o viver e o compreender. Como, elemento analisado pelo discurso eclesiástico, a roupa seria destituída de poder.

Contudo, todos os aparatos que se combinavam na elaboração dos trajes sacros, do colorido à riqueza, não constituíam por si a expressão do poder daqueles que a usavam? Não investia o bispo de autoridade no trato com o simplório abade? Ela, a roupa, objeto significante da autoridade eclesial, não construía e era construída por significados culturais forjados no contexto social daquelas relações?

Antes de darmos conta desta questão, continuaremos a analisar outras facetas do discurso da ordem no mundo medieval. 
Da mesma forma tripartide que o Universo foi classificado e hierarquizado a sociedade foi concebida e, na medida do possível, assim organizada. Portanto, a procura da ordem se manifestou em todos os níveis, constituindo verdadeiros estamentos na sociedade medieval, que se convencionou chamar de clérigos, nobreza e povo. Estas partes eram concebidas e doutrinadas pela idéia da absoluta necessidade de uma ordem entre elas, fazendo com que, tal como no Reino dos Céus, a trindade se formasse em um único ser, sendo três em um - o povo de Deus.

A falta de unidade, dentro de um imaginário tão fundamentado na ordem, como foi o medieval, é sinônimo de desordem, corrupção e perigo. Pertencer ao Reino de Deus é ser convicto da verdade proposta e compartilhar desta certeza é eliminar do campo do imaginário as possibilidades de escolha, do diferente, da tolerância e mesmo da igualdade entre os seres. Ao homem medieval não cabia escolher, mas ser escolhido por Deus (QUEIROZ, 1988, p.45). A escolha da criatura, desprovida da verdade mesmo sendo contida do macrocosmo, torna-se um perigo. Ela pode colocar toda a ordem cósmica fora de seu eixo.

$\mathrm{Na}$ medida desta concepção a variação na produção da vestimenta é algo inconcebível, mantê-las tal como "a tradição" às concebeu é respeitar a ordem, é reconhecer sua posição dentro do estamento a que pertence, é viver conforme a vontade de Deus. A moda, enquanto sistema, não teve qualquer possibilidade de nesta sociedade produzir-se. Mas, nem por isso, 
as roupas deixaram na ausência de sua variabilidade de expressar o fundamento da ordem que unificava toda a sociedade. De criar insígnias aos corpos que elas cobriam.

O corte rígido, a cor oficial, os símbolos bordados às capas são exemplos da expressão desta ordem. Analisando a indumentária dos bispos podemos melhor evidenciar nossos argumentos. Estes eram, dentro da ordem eclesial, considerados nobres de alta hierarquia que dedicavam suas vidas à Igreja. Governavam e viviam de maneira bem semelhante aos nobres. Alguns desses clérigos eram tão ricos e poderosos quanto os maiores senhores militares. Sua indumentária de celebração era a própria ostentação deste poder. Muitíssimo suntuosa e bem ornamentada demonstrava o poder divino do qual estavam investidos e demarcavam sua posição em relação os demais membros de suas comunidades.

Estes trajes eram encimados pela mitra, que acompanhada do báculo representavam todo seu poder e posição privilegiada na relação com o Criador. O báculo de um Bispo tinha a ponta arredonda representando o limite de seu poder a uma comunidade, enquanto do Papa tinha um acabamento em cruz, dando evidência que seu poder era transcendente a toda Cristandade.

Usavam, os bispos, uma túnica branca para cobrir diretamente a pele, sobreposta vinha outra na cor dos paramentos do dia e por último uma casula. Essa se apresentava bordada ou estampada em tecido contrastante e solene. Poderia ser em branco, verde, roxo, vermelho ou preto. Estas cores eram selecionadas 
conforme a importância do evento eucarístico, sendo o vermelho nas celebrações dos mártires, santos que deram seu sangue pela glória do cristianismo. 0 roxo, em verdadeiro sentimento de luto e reserva espiritual, na Quaresma e Advento. 0 verde, na simbologia da ressurreição, depois da Páscoa até o Advento. Esta casula, também, poderia ser bordada com símbolos eucarísticos (Santíssima Trindade, Mistério da Redenção, Cruz, Lírio que representava castidade e pureza ou Rosa, que simbolizava o amor). Acompanhava ainda 0 detalhe do manípulo, usado como um lenço e os sapatos que sempre deveriam ser da cor do paramento.

Toda a expressividade do traje dava conta tanto de evidenciar o poder espiritual de quem o vestia como indicá-lo aos demais, que jamais poderiam usufruí-lo, devido a distância social e espiritual que ficava marcada por aqueles tecidos, formas e cores.

A mesma ordem que se expressa claramente nos trajes eclesiásticos também ordenava, hierarquicamente, o conhecimento: o mais primário deles era o proporcionado pelo corpo - a Sensação - percepção da paixão sofrida por um órgão corporal; no grau intermediário encontrava-se a Ciência - discernimento ou juízo das coisas corporais; já na posição mais elevada e à qual todo homem deveria se esforçar para alcançá-la encontrava-se a Sabedoria contemplação das verdades eternas, a própria salvação porque na medida em que se alcançava esta, o homem passava a viver em contemplação no "seio do Senhor criador de toda verdade." 
Como fica evidente à análise, o conhecimento dos princípios universais estava separado da experiência concreta. Esta jamais poderia proporcionar a verdade na medida em que se realizava a partir da sensação, sempre vil e pecaminosa, pois distante do espírito. Só em Deus e nas coisas que estão em Deus poderíamos, segundo Agostinho, encontrar o verdadeiro conhecimento. Este constituído pelas Idéias, formas originárias, razões estáveis e imutáveis das coisas pertencem a Deus. Elas não são criaturas, não nascem, nem morrem, apenas participam da Sabedoria eterna, onde se funda a natureza das coisas e os juízos verdadeiros que delas formamos (QUEIROZ, 1988).

Mesmo concebendo a verdade sobre estes parâmetros e afirmando que para alcançá-la todo homem precisaria da revelação de Deus, Santo Agostinho não negou a validade da razão para que a criatura alcançasse a Sabedoria. Através dela o homem percebia o mundo, este como reflexo do mundo das idéias, não conteria a verdade em si, mas através do raciocínio, da análise, da reflexão poderia o homem perceber os indícios da verdade, que conseqüentemente levaria-o a assegurar a validade da fé, e quanto mais convicto da fé mais próximo estaria de receber a revelação de Deus. Portanto, a razão seria o primeiro vôo do espírito em direção ao seu criador e ao passo que a contemplação se fizesse plena a fé não seria mais necessária, pois não precisaríamos crer em Deus já que viveríamos nele (GILSON, 1991). Em um de seus versículos prediletos a sua verdade se expressava: "Compreende para crer, crê para compreender." (Isaías). 
A compreensão do saber nesta escala de proximidade com Deus fazia com que o material, o sensível, fosse desprezado e o padrão estético que se compõem entre os eclesiásticos muito dissesse respeito a este desprezo, principalmente, quando o gótico, como estilo arquitetônico adquire importância e vazão na Europa.

Entre o século XI e XII, como nos cabe situar, a Europa Ocidental viveu uma intensa reformulação em suas condições de vida. Tal como afirma DUBY, estes foram séculos de "grande progresso", caracterizado simultaneamente por uma expansão demográfica acentuada e pela difusão de novas técnicas que deram impulso à produção agrícola e artesanal. Estas novas condições reelaboraram valores, distanciaram o sagrado do profano, que durante tanto séculos confundiram-se, e o profano, tantas vezes malbaratado pela transcendência religiosa, adquiriu certa autonomia. A salvação, por tanto tempo fixada como objetivo único do homem, perde espaço para uma mentalidade de lucro e mobilidade social que se constitui na experiência das emergentes feiras, cidades e atividades comerciais manufatureiras.

No plano teológico, as idéias de Santo Agostinho começaram a serem revistas pelos mestres da Escola de Chartres, especialmente quando refletiram sobre o sentido da criação e chegaram à conclusão que "longe de ser um simples reflexo degradado das esferas celestes, o universo tinha uma realidade própria que podia ser objeto de estudos e interpretação" (VAUCHEZ, 1995, p.69). 
Todavia, todas estas inquietações e mudanças econômicas e sociais não provocaram uma ruptura geral com as concepções religiosas baseadas em Santo Agostinho, mas ao invés disso as reforçaram. Pois, no desespero de não se perder nas rajadas dos novos ventos, boa parte da Igreja Católica, reafirmou velhos conceitos, impôs novas determinações e fechou as portas à reflexão e transformação de suas relações com o mundo. Contudo, por outro lado, uma fantástica transferência de valorização do Reino de Deus para a natureza, das coisas últimas para 0 ambiente imediato, dos tremendos mistérios escatológicos para os segredos mais inofensivos do mundo das criaturas foi efetuada, a partir do pensamento de Aristótoles, por São Tomás de Aquino.

Este pensador ao tomizar o grego, também, criou uma justificação teológica para o naturalismo ${ }^{3}$ que durante os séculos góticos tomaram impulso na Europa do final da Idade Média. E é através dele que se conciliam as oposições de resistência e apoio aos novos tempos.

Desta forma, mesmo num contexto de intensa mudança e contradições, ao analisarmos os trajes eclesiásticos medievais do século XII constataremos a expressão da rigidez e luta pela manutenção de valores que eram altamente embatidos pelas mudanças estruturais que a

${ }^{3}$ São palavras de São Tomás de Aquino a respeito desta questão: "Deus gosta de todas as coisas, pois cada uma delas está em harmonia com Sua essência." Apud. HAUSER, 1994. p. 236. 
sociedade medieval passava, ao lado de uma espiritualidade toda especial que o naturalismo constituía.

No dia-a-dia o desejo de reatar com a perfeição da Igreja primitiva resignificou o ideal de vida apostólica. O Cristo é revalorado, seu Testamento (o novo) tornou-se capaz de fornecer todas as regras de vida. A pobreza, a humildade, o desprezo das coisas do mundo ganham novo impulso e deles surgem muitas ordens eclesiásticas, como a de São Francisco de Assis.

O padrão estético, portanto, no círculo eclesiástico se simplifica e espiritualizam-se, os hábitos, tanto feminino quanto masculino, os quais revelam o desapego à elaboração e suntuosidade. Procuram, acima de tudo, opor frontal contraste entre $o$ mundo que se corrompe na luxúria e eles que se preservam no bem.

HAUSER, analisando o período em questão afirma:

“O idealismo no período gótico era, ao mesmo tempo, um naturalismo que procurava representar figuras espirituais e ideais, com raízes num mundo supersensivel, de uma maneira que também fosse empiricamente correta. Nisso, a arte concordava com o idealismo filosófico da época, o qual sustentava que as idéias não estavam separadas, mas integradas em determinadas coisas, assim corroborando a realidade das idéias e dos particulares. (...) O elemento novo consiste numa intimidade e profundidade de expressão por meio das quais o artista faz de qualquer 
obra de arte gótica ou pós-gótica uma espécie de confissão de fé pessoal" (HAUSER, 1994, p.240-248).

0 traje eclesial esteve nesta circunstância histórica desvencilhado com todas estas questões, tendendo a prevalecer a sobriedade e a resistência em forma de uma simplicidade exacerbada, que levou as diversas ordens mendicantes a adotarem 0 uso dos pés descalços. Este é o caso dos frades capuchinho. São eles uma divisão da ordem franciscana. Apegavam-se às normas da congregação, com votos de pobreza, andar descalço e rejeição de qualquer forma de riqueza. Vestiam-se, e até hoje mantêm os hábitos, com um manto que alcançava o final das pernas, usavam capuz que protegia a cabeça raspada, chamada de tonsura, que era um signo do pertencimento à congregação. Na cintura atavam um cordão com vários nós, como símbolo da fé, da esperança, caridade e penitência assim respectivamente figuradas. A tonsura, em especial, revelava ao monge que a utilizava o abandono de toda a vaidade e a vida consagrada a Deus. Era o sinal de pertencimento a um mundo além da matéria.

Portanto, seus trajes entre a multidão ou na reclusão de seus mosteiros denotavam a distância e a despreocupação com o mundo do lucro e das inovações tecnológicas que rapidamente se davam. Abdicavam do futuro para viverem como simples peregrinos primitivos em seus trajes mais precários. A cor marrom, tão pálida e desprovida de significados nas anteriores hierarquias, também, dava conta de falar do valor dado ao espírito, muito acima da matéria. 
Os monges cartusianos, por sua vez, eram especialistas no trato com a terra. Retiraram-se para os bosques e pontos distantes das intensas feiras medievais. Porém em torno deles, cidades se constituíram no interesse de suas sedes serem protegidas pela beatitude daqueles homens, que em suas simples vestes apenas procuravam abrigo do frio e das chuvas. Usavam uma túnica de tecido branco, escapulário e por cima um manto negro com capuz, o qual era pregueado nos ombros, compondo um tipo de uma pala com capuz.

Nem só os mais convictos da fé, que abdicavam do mundo e entravam para os mosteiros, envergavam a simplicidade e a insígnia do apego a espiritualidade. Muitos foram os homens que adentraram pelo campo religioso através da prestação de socorro aos feridos das Cruzadas e da hospedagem de peregrinos. Estes são os casos do Cavaleiro da Ordem Teutônica e dos Cavaleiros da Ordem - Hospitaleiros. Surgiram de uma organização de caridade ligada a um hospital de Cruzadas. Os primeiros se vestiam com uma capa branca com uma cruz preta que the indicava o poder de representar a Igreja Católica. Os outros usavam simplesmente um manto preto com uma cruz branca de pontas bifurcadas. A esta capa, às vezes, se acompanhava gola e punhos sobrepostos.

Enfim, pelos mais diversos meios a simplicidade evidencia-se nas vestimentas de padres e religiosos que durante o século XIII projetavam um mundo ideal, no qual a simplicidade e pureza de espírito salvariam a todos. 
Para concluir nossa discussão nos falta abordar a idéia de história que o homem medieval compôs. Esta não se fez a parte de nenhuma questão, muito ao contrário, se realizou vinculada estreitamente à concepção da ordem e do saber que já expusemos anteriormente.

O conhecimento histórico mesmo no século $\mathrm{XI}$ e seguintes se produziu, totalmente, tutelado pela ação da Igreja, o que explica o sentido que adquiriu. Ele se compôs na proposta ideológica de revelar ao homem o desejo divino, ou seja, a ação de Deus sobre a Terra. Não lhes motivou qualquer desejo, como aconteceu aos gregos e romanos, de arrancar o passado do esquecimento e dele tirarem lições práticas para a vida dos impérios. Sua preocupação fundamentava-se em discernir como a obra da salvação se realizaria. Como desde o advento da vinda do Cristo os homens eram empurrados pela vontade divina em direção ao Juízo final e sua conseqüente redenção de todos os pecados humanos. Eles buscavam Deus na história dos homens (MOMIGLIANO, 2004).

Sua lógica fundamentava-se na idéia de que estando todo o Universo encadeado na ordem divina nada ocorria que fugisse a esta dimensão e por este parâmetro, mesmo os eventos mais particularizados, estavam vinculados à vontade do Criador, cujo objetivo era realizar sobre a Terra a "Cidade de Deus", como Santo Agostinho intitulara.

Segundo a ótica destes historiadores os acontecimentos pesquisados e descritos evidenciavam os sinais de crescimento da Igreja, 
já que esta era a mensageira direta da vontade de Deus, encarregada de preparar os homens para o advento da redenção. Além disso, os fatos também denunciavam a aproximação da Parusia e alertavam ao homem a emergência de sua remição. Assim sendo, todas as guerras, epidemias e inclusive todos os fenômenos naturais se inseriam como eventos históricos que, organizados por Deus, colocavam seus filhos à prova. A vitória ou a derrota na guerra era a prova inconteste do apreço de Deus por uns, os justos, e seu castigos para outros, os injustos. Portanto, a justiça de Deus é imanente a todos os acontecimentos e como tal, "nunca falha" (LE GOFF; SCHMITT, 2006).

Esta compreensão, altamente coerente para o pensamento da época, nos permite pensar qual o papel que o sujeito histórico adquire nesta lógica. Dentro desta percepção ser sujeito histórico não é uma condição possível a todos que vivem em sociedade, muito ao inverso. Ser sujeito histórico é ser alguém que se confunde com os heróis e os santos. É ser alguém especial e particular, de grande importância e indispensável aos fatos históricos. $E$, estes sujeitos, portanto, eram aqueles que tomados da Graça realizavam os grandes feitos. Pois adquirir a graça de vencer, o poder de se sobrepor sobre os inimigos, fosse o outro povo ou a epidemia, só seria possível mediante a vontade de Deus. E como a doutrina afirmava: ser agraciado por Ele é privilégio dos santos, daqueles que transcenderam a precariedade das percepções sensíveis e, usando da razão a serviço da fé, domaram os ímpetos do pecado e receberam a revelação divina. 
Assim sendo, o homem nada produz, tudo lhe está dado. Ofertado pela autoridade máxima do Universo. Não the cabe escolher, duvidar, desejar o outro. Propor-se a tal ousadia é inverter a própria história. Tanto a sua história, condenando-se ao Inferno eterno, quanto à dos outros thes retardando a chegada ao Paraíso. Então, como não acatar a ordenação do trajar, não manter inscrito em seu vestuário seu lugar no mundo, na hierarquia do Universo?

Para os homens e mulheres que viveram a efervescência dos séculos XI e XII, e os subseqüentes, 0 grande desafio se fez exatamente em romper com a ordem que poderia thes significar a negação da própria eternidade. Aos homens de Igreja não lhes cabia o desafio tácito, deveriam e foram o repositório das mais rígidas tradições e em seus hábitos o tempo procurou parar.

As ordens mendicantes que no bojo destes debates se formaram, até hoje, bem representam o apego à sobriedade e simplicidade dos trajes. Este é o caso dos monges Franciscanos que, ainda na atualidade, podemos encontrar com a mesma indumentária, a qual recebeu o acréscimo do calçado. Continuam usando um manto simples marrom com capuz e um cordão na cintura, simbolizando sua castidade e pureza. Esta indumentária originou-se de um manto de leproso doado a São Francisco de Assis quando de sua conversão e como tal representa o apego a caridade, aos oprimidos e sofredores (BRUHN, 1994).

Se os tempos atuais são de verdadeiro entrelaçamento da Igreja com o povo e de busca 
de uma maior aproximação entre leigos e clérigos não há mais sentido em delimitar estas distâncias através de hábitos eclesiais, tão usados algumas décadas atrás. Contudo, ainda nas consagrações, nos rituais íntimos de avanço na hierarquia eclesial o uso de vestimentas apropriadas é feito. A imagem da freira Cartusiana medieval não é algo incompreensível aos padres da atualidade. Eles bem conhecem todos aqueles paramentos que a acompanham a investidura de uma irmã à congregação.

Os ornamentos para essas ocasiões eram especiais. Usavam uma túnica branca de algodão e o escapulário, que se mantinha preso através de faixas. Um longo manto branco passava pela cabeça e pelo pescoço, não deixando nenhuma parte do corpo exposto, com exceção do rosto e mãos. Um véu marrom, que representava sua condição de noiva do Cristo, acompanhava uma estola azul adornada com cruzes douradas. Como adereços levavam uma faixa azul sobre o braço esquerdo e uma vela acesa à mão. A vela e a coroa de cinco pontas, colocada sobre o véu, simbolizavam toda a consagração, fé e batismo que a nova irmã fazia (BRUHN, 1994).

Se hoje as circunstâncias históricas são bem adversas para evidenciar-se pelos trajes a distância entre o mundo do clero e o mundo dos filhos de Deus, na intimidade dos recintos castos a manutenção das tradições medievais se fazem com grande pompa. A dualidade desta situação invés de desfazer a possibilidade de interpretação do discurso eclesiástico atual a permite, exatamente, pela medida do silêncio e 
das transformações pelas quais a Igreja Católica Contemporânea passou.

Para sairmos pela mesma porta que entramos, e voltarmos infinitamente, concluímos com termos de Elizabeth Wilson:

"Tem-se uma sensação estranha quando se olha para essas roupas que tiveram uma relação íntima com seres humanos que há muito tempo foram para o túmulo, porque o vestuário é uma parte tão próxima dos nossos eus vivos e em movimento que, assim petrificados para serem exibidos em mausoléus da cultura, dão-nos um vislumbre de qualquer coisa só parcialmente entendida, sinistra, ameaçadora; a atrofia do corpo e a evanescência da vida." (WILSON, 1989, p.11).

\section{Referências Bibliográficas}

BRUHN, Wolfgang Max. A Pictural History of Costume. Tilke, 1994.

DEMURGER, Alain. Os cavaleiros de Cristo: templários, teutônicos, hospitalários e outras ordens militares na Idade Média (sécs. XI-XVI). Rio de Janeiro: Jorge Zahar Editor, 2002.

GILSON, Étienne. A filosofia Medieval. Petrópolis : Vozes, 1991.

HAUSER, Arnold. História Social da Arte e da Literatura. São Paulo: Martins Fontes, 1994.

LE GOFF, Jacques; SCHMITT, Jean-Paul. Dicionário Temático do Ocidente Medieval. Bauru: EDUSC, 2006. 
MOMIGLIANO, Arnaldo. As Raízes Clássicas da Historiografia Moderna. Bauru: EDUSC, 2004 OS PENSADORES. Santo Agostinho - Confissões. São Paulo : Nova Cultural, 1996.

PÉPIN, Jean. Santo Agostinho e a Patrística Ocidental. In: CHÂTELET, François. A Filosofia Medieval. vol. 2. Rio de Janeiro : Zahar, 1974. QUEIROZ, Tereza A.P. de. As heresias medievais. 4a. ed. São Paulo: Atual, 1988.

STEENBERGHEN, Fernand von. História da Filosofia - Período Cristão. Coimbra: Gradiva, 1984.

VAUCHEZ, André. A Espiritualidade na Idade Média Ocidental. Rio de Janeiro: Zahar, 1995.

WILSON. Elizabeth. Enfeitada de Sonhos. Lisboa : Edições 70, 1989.

\section{Entrevista}

Monsenhor Agostinho Stahelin, concedida à Madalena dos Santos, nas dependências da Paróquia de São Judas Tadeu, do distrito de Barreiros, São José, S/C, em maio de 1998. 